\title{
QUALIDADE DE MAÇÃS 'ROYAL GALA' SUBMETIDAS AO DANO MECÂNICO POR IMPACTO E APLICAÇÃO DE 1-METILCICLOPROPENO EM DOIS SISTEMAS COMERCIAIS DE ARMAZENAMENTO ${ }^{1}$
}

\author{
MARCOS VINICIUS HENDGES², CRISTIANO ANDRÉ STEFFENS ${ }^{3}$, \\ LUCIMARA ROGÉRIA ANTONIOLLI ${ }^{4}$, CASSANDRO VIDAL TALAMINI DO AMARANTE ${ }^{3}$, \\ AURI BRACKMANN ${ }^{5}$
}

RESUMO - O objetivo deste trabalho foi avaliar os efeitos do dano mecânico por impacto e da aplicação de 1-metilciclopropeno (1-MCP) sobre a qualidade de maçãs 'Royal Gala' mantidas em armazenamento refrigerado (AR) e em atmosfera controlada (AC). Os tratamentos avaliados foram dano mecânico (sem e com dano por impacto $)$ combinado com a aplicação de 1-MCP $\left(0\right.$ e $\left.625 \mathrm{~nL} \mathrm{~L}^{-1}\right)$. Os frutos foram armazenados durante quatro meses em armazenamento refrigerado (AR; $0{ }^{\circ} \mathrm{C} \pm 1{ }^{\circ} \mathrm{C}$ e $92 \pm 2 \%$ de UR) (experimento 1) e durante oito meses em atmosfera controlada (AC; $1,2 \mathrm{kPa}$ de $\mathrm{O}_{2}+2,0 \mathrm{kPa}$ de $\mathrm{CO}_{2} ; 0{ }^{\circ} \mathrm{C} \pm 0,1^{\circ} \mathrm{C}$ e $96 \pm 2 \%$ de UR) (experimento 2). Em AR, os frutos tratados com 1-MCP apresentaram maior firmeza de polpa, além de maior área escurecida no local danificado, na saída da câmara. Nesta condição de armazenamento, após sete dias em condição ambiente, os frutos tratados com 1-MCP apresentaram acidez titulável mais elevada, maior escurecimento da epiderme e menor profundidade de escurecimento da polpa no local danificado. Em AC, a aplicação do 1-MCP proporcionou, após a saída da câmara, frutos com menor teor de sólidos solúveis e maior escurecimento da epiderme no local danificado, sendo que, após sete dias em condição ambiente, os frutos apresentaram maior profundidade de escurecimento do tecido da polpa no local danificado. $\mathrm{O}$ dano por impacto ocasionou escurecimento da polpa de maçãs 'Royal Gala'. O 1-MCP não inibiu os efeitos do dano, mas preservou a qualidade dos frutos, especialmente em AR.

Termos para indexação: amadurecimento, etileno, armazenamento refrigerado, atmosfera controlada.

\section{QUALITY OF 'ROYAL GALA' APPLES SUBMITTED TO IMPACT INJURY AND APPLICATION WITH 1-METHYLCYCLOPROPENE IN TWO COMMERCIAL STORAGE SYSTEMS}

\begin{abstract}
The objective of this study was to evaluate the effects of impact injury and treatment with 1-methylcyclopropene (1-MCP) on the quality of 'Royal Gala' apples in cold storage (CS) and controlled atmosphere condition (CA). The treatments were impact injury (with and without impact injury) combined with 1-MCP $\left(0\right.$ and $\left.625 \mathrm{~nL} \mathrm{~L}^{-1}\right)$. The fruits were stored for four months in $\mathrm{CS}\left(0^{\circ} \mathrm{C} \pm 1^{\circ} \mathrm{C}\right.$ and $\left.92 \pm 2 \% \mathrm{RH}\right)$ (experiment 1) and for eight months in $\mathrm{CA}\left(1.2 \mathrm{kPa} \mathrm{O}_{2}+2.0 \mathrm{kPa} \mathrm{CO}_{2}, 0^{\circ} \mathrm{C} \pm 0.1^{\circ} \mathrm{C}\right.$ and $\left.96 \pm 2 \% \mathrm{RH}\right)$ (experiment 2). In CS, fruits treated with 1-MCP showed higher flesh firmness, besides larger darkened area in the damaged place, at removal from storage. After CS followed by seven days at an ambient conditions, fruits treated with 1-MCP showed higher titratable acidity, skin darkening and smaller darkening depth of flesh in the place of the damage. In CA, 1-MCP application resulted, at removal from CA storage, fruits with lower levels of soluble solids content and higher skin darkening in the place of the damage, and, after seven days of shelf life, fruit showed greater depth of darkening of the pulp in the damaged place. The impact injury caused darkening of the pulp of apples 'Royal Gala'. 1-MCP did not inhibit the effects of impact injury, but preserved fruit quality, especially in CS.
\end{abstract}

Index terms: ripening, ethylene, cold storage, controlled atmosphere.

\footnotetext{
${ }^{1}$ (Trabalho 071-10). Recebido em: 15-03-2010. Aceito para pubilcação em: 13-08-2010.

${ }^{2}$ Mestrando em Produção Vegetal, Universidade do Estado de Santa Catarina (UDESC). Av. Luiz de Camões, 2090, Bairro Conta Dinheiro, 88520-000, Lages-SC, Brasil. E-mail: marcos_hendges@hotmail.com

${ }^{3}$ Professor do Departamento de Agronomia, UDESC, Lages-SC, Brasil. E-mail: steffens@cav.udesc.br; amarante@cav.udesc.br ${ }^{4}$ Pesquisadora da Embrapa Uva e Vinho. Rua Livramento, 515, Caixa Postal 130, 95700-000, Bento Gonçalves-RS, Brasil. E-mail: lucimara@cnpuv.embrapa.br

${ }^{5}$ Professor do Departamento de Fitotecnia, Universidade Federal de Santa Maria (UFSM). Av Roraima, 1000, Bairro Camobi, $97105-$ 900, Santa Maria-RS, Brasil. E-mail: brackman@ccr.ufsm.br
} 


\section{INTRODUÇÃO}

Os consumidores estão cada vez mais exigentes, aumentando assim a demanda por frutos com alto padrão de qualidade, contudo nem sempre esse padrão é alcançado, uma vez que os mesmos estão suscetíveis a fatores estressantes que podem causar a perda prematura de qualidade.

Impactos e vibrações durante a colheita, transporte e classificação podem ocasionar danos mecânicos, os quais são responsáveis por consideráveis perdas de qualidade na cadeia produtiva, desde o produtor até o consumidor (DINTWA et al., 2008). De acordo com Barchi et al. (2002), os danos mecânicos são responsáveis pela deterioração de frutos e vegetais, sendo estimadas perdas médias de $35 \%$.

Dentre os danos mais comuns, destacam-se os causados por impacto, compressão e corte (SANCHES et al., 2008). Esses danos podem desencadear inúmeras respostas fisiológicas (MATTIUZ; DURIGAN, 2001a), como alterações no metabolismo, no aroma e no sabor (MORETTI; SARGENT, 2000), escurecimento da polpa, além do aumento na taxa respiratória e de produção de etileno (MATTIUZ; DURIGAN, 2001a; DE MARTINO et al., 2006).

O etileno é considerado o hormônio do amadurecimento, por ser capaz de acelerar este processo. $\mathrm{O}$ dano mecânico que um fruto sofre, pode aumentar a produção desse hormônio e, consequentemente, acelerar o processo de amadurecimento do fruto e reduzir seu período de comercialização (STEFFENS et al., 2008). De acordo com Lewis et al. (2008), o dano mecânico, provocando amassamento e escurecimento do fruto, tem causado perdas de até $50 \%$ em maçãs.

Como forma de redução de perdas e controle da oferta de maçãs ao consumidor, utilizam-se diferentes tecnologias de armazenamento, algumas bastante difundidas comercialmente, como o caso do armazenamento refrigerado (AR) e da atmosfera controlada (AC), os quais podem estar associados ao uso do 1-metilciclopropeno (1-MCP). O armazenamento em condição de AC retarda substancialmente o amadurecimento dos frutos (CHITARRA; CHITARRA, 2005). Além disso, o 1-MCP, por ser um produto que inibe a ação do etileno, pode ser uma alternativa para retardar a indução do amadurecimento desencadeado pelo dano mecânico (DAL CIN et al., 2006). Este produto atua ligando-se irreversivelmente ao sítio de ligação do etileno, impedindo que o mesmo se ligue a seu receptor e assim desencadeie o processo de amadurecimento dos frutos (DE MARTINO et al., 2006). Em damascos (DE MARTINO et al., 2006) e maçãs (STEFFENS et al., 2008), o surgimento de uma região escurecida na região lesionada foi retardado pelo uso do 1-MCP. Este efeito do 1-MCP pode estar relacionado à menor atividade da enzima polifenoloxidase (WATKINS, 2006).

Apesar de existir um consenso quanto ao efeito do dano mecânico na perda da qualidade de frutos armazenados, não existem informações no Brasil sobre os efeitos do dano por impacto em maçãs. Além disso, alguns trabalhos não observam efeito do dano mecânico na produção de etileno em mamões (QUINTANA; PAULL, 1993), na atividade respiratória de tomates (KAAYA; NJOROGE, 2004) e de mamões (QUINTANA; PAULL, 1993). Provavelmente, a divergência entre os trabalhos deve-se ao tipo, intensidade e susceptibilidade dos frutos ao dano a que foram submetidos.

Sendo assim, este trabalho teve como objetivo avaliar o efeito do dano mecânico por impacto e da aplicação de 1-metilciclopropeno (1-MCP) sobre a qualidade de maçãs 'Royal Gala' mantidas sob armazenamento refrigerado (AR) e em atmosfera controlada (AC).

\section{MATERIAL E MÉTODOS}

Os frutos utilizados neste trabalho foram colhidos em um pomar comercial no município de Vacaria-RS, na safra de 2007/2008. Depois de colhidos, os frutos foram colocados em bandejas, e estas em caixas plásticas, cada uma contendo três bandejas sobrepostas. Posteriormente, os frutos foram transportados para o Laboratório de Fisiologia e Tecnologia Pós-Colheita da Embrapa Uva e Vinho, onde foram aplicados os tratamentos.

O dano mecânico foi aplicado na região equatorial do lado mais vermelho dos frutos, através da queda livre, de uma altura de $20 \mathrm{~cm}$, sobre uma superfície metálica indeformável. Para isso, utilizou-se um equipamento de sucção, semelhante ao utilizado por Magalhães et al. (2007), composto por uma bomba de vácuo (marca Fisatom, potência de 300 Watts), conectada, através de uma tubulação de silicone, a uma tampa recortada de dessecador fixa a uma haste de 1,20 $\mathrm{m}$ de altura. No orifício da tampa, foi conectado um tubo de PVC de $40 \mathrm{~mm}$, contendo uma ventosa que permite a aderência do fruto através do processo de sucção. A base do equipamento consistiu em uma chapa de ferro.

Depois de regulada a altura da queda, a bomba foi ligada, e, deste modo, os frutos permaneceram suspensos, presos à ventosa, através da força gerada pelo vácuo. Com o desligamento da bomba, na ausência de vácuo, ocorre a queda livre do fruto. Na base do equipamento, foi colocado pó de giz, permitindo que, a cada queda, o fruto fosse marcado na região 
do impacto e, posteriormente, assinalado com caneta preta, para a identificação do local da lesão. Antes da aplicação do dano, os frutos foram pesados individualmente e separados por calibre, sendo regulada a altura de queda para cada calibre.

Após o dano, os frutos receberam ou não tratamento com 1-MCP na dose de $625 \mathrm{~nL} \mathrm{~L}^{-1}$. Para aplicação do produto, foi utilizada câmara hermética com volume de $0,45 \mathrm{~m}^{3}$, onde os frutos permaneceram durante 24 horas a $20^{\circ} \mathrm{C}$.

Parte dos frutos foi mantida durante quatro meses em sistema de armazenamento refrigerado (AR; $0 \pm 1{ }^{\circ} \mathrm{C}$ e $92 \pm 2 \%$ de UR), na Embrapa Uva e Vinho, correspondendo ao experimento 1, constituído de cinco repetições de cinco frutos, avaliados na saída da câmara e, após a saída, mais sete dias em condição ambiente. Outra parte dos frutos foi transportada para o Núcleo de Pesquisa em Pós-Colheita da Universidade Federal de Santa Maria, em Santa Maria-RS, correspondendo ao experimento 2. Neste experimento, foram utilizadas cinco repetições de 15 frutos para cada tratamento, com armazenamento durante oito meses em condição de $\mathrm{AC}(1,2 \mathrm{kPa}$ de $\mathrm{O}_{2}+2,0 \mathrm{kPa}$ de $\mathrm{CO}_{2} ; 0 \pm 1{ }^{\circ} \mathrm{C}$ e $96 \pm 2 \%$ de UR) e avaliados na saída da câmara e, após a saída, mais sete dias em condição ambiente.

Após o período de armazenamento, os frutos foram recolocados em bandejas, e estas, em caixas plásticas e encaminhados ao Laboratório de Pesquisa em Fisiologia Vegetal e Pós-Colheita da Universidade do Estado de Santa Catarina (UDESC), localizado em Lages-SC, onde foram avaliados quanto aos atributos de firmeza de polpa, acidez titulável (AT), sólidos solúveis (SS), escurecimento da epiderme e da polpa no local do dano, e área e profundidade do dano, logo após a saída da câmara e, depois de sete dias, em condição ambiente.

Para a medida da firmeza de polpa $(\mathrm{N})$, removeu-se uma porção da epiderme e, com auxílio de um penetrômetro equipado com ponteira de $11 \mathrm{~mm}$ de diâmetro, fez-se a medida na região equatorial dos frutos, intermediária entre o local do dano e o local oposto ao dano. Os valores de AT (meq de ácido málico $100 \mathrm{~mL}^{-1}$ ) foram obtidos por meio de uma amostra de $10 \mathrm{~mL}$ de suco dos frutos, previamente extraída de fatias transversais retiradas da região equatorial das maçãs, e triturada em uma centrífuga elétrica. Esta amostra foi diluída em $90 \mathrm{~mL}$ de água destilada e titulada com solução de hidróxido de sódio $0,1 \mathrm{~N}$ até $\mathrm{pH} 8,1$.

Os teores de SS ( ${ }^{\circ}$ Brix) foram determinados por refratometria, utilizando-se do suco extraído, conforme descrito para a AT, sendo realizada a correção do efeito da temperatura $\left(20^{\circ} \mathrm{C}\right)$. A quantificação do escurecimento da epiderme e da polpa no local do dano foi feita através da medição da luminosidade (L), que varia de 0 (preto) a 100 (branco), com um colorímetro Minolta, modelo CR 400. Para as medidas da área de tecido escurecido, no local danificado, retirou-se a epiderme e, com auxílio de um paquímetro digital, efetuaram-se as medidas transversal e longitudinal do dano. Tais medidas foram utilizadas no cálculo da área da elipse $(\mathrm{A}=\pi \mathrm{ab}$; em que: "a" e "b" correspondem à metade da medida transversal e longitudinal, respectivamente).

Para a medida da profundidade de escurecimento, foi retirada amostra da polpa com um furador de rolhas, sendo mensurada a profundidade de tecido escurecido a partir da superfície da epiderme.

Os tratamentos foram organizados em um bifatorial (sem e com dano mecânico por impacto versus sem e com aplicação de 1-MCP). O delineamento utilizado foi em blocos ao acaso, sendo os dados submetidos à análise de variância (ANOVA). Para a comparação das médias, adotou-se o teste de Tukey $(\mathrm{P}<0,05)$, a $5 \%$ de probabilidade.

\section{RESULTADOS E DISCUSSÃO}

Na colheita, os frutos apresentavam firmeza de polpa de $79,97 \mathrm{~N}$, AT de 5,3 meq $100 \mathrm{~mL}^{-1}$, teor de SS de $11,5^{\circ}$ Brix e valor $L$ (para quantificar o escurecimento no local danificado após o impacto) de 41,96 para a epiderme e 83,13 para a polpa.

$\mathrm{O}$ dano mecânico não afetou a firmeza de polpa, em ambos os sistemas de armazenamento e períodos de avaliação (Tabela 1). Steffens et al. (2008) também não observaram efeito do dano mecânico sobre a firmeza de polpa de maçãs 'Gala' mantidas sob condição ambiente. Contudo, em outros frutos, tem-se observado que o dano mecânico acelera a redução da firmeza de polpa (MATTIUZ; DURIGAN, 2001b; DE MARTINO et al., 2006). Mattiuz e Durigan (2001b) citam que alguns frutos podem ser mais sensíveis que outros ao dano mecânico, devido às suas características físicas, como tamanho, peso e grau de hidratação celular.

Em AR, frutos tratados com 1-MCP apresentaram maior firmeza de polpa nos dois períodos de avaliação, independentemente da aplicação de dano mecânico (Tabela 1), com valor superior ao mínimo utilizado como padrão (60 N) (CORRENT et al., 2004). Brackmann et al. (2004), trabalhando com a cultivar Gala em AR, também observaram maior firmeza de polpa em frutos tratados com 1-MCP. A maior firmeza de polpa nos frutos tratados com 1-MCP está diretamente relacionada à redução na 
ação e produção do etileno. O etileno aumenta a atividade das enzimas responsáveis pela perda de firmeza de polpa (MAJUMDER; MAZUMDAR, 2002).

Contudo, em AC, não foi observado efeito do 1-MCP na manutenção da firmeza de polpa. Brackmann et al. (2008) também não observaram efeito do 1-MCP na manutenção da firmeza de polpa, na saída da câmara, em maçãs 'Gala' armazenadas em AC. Em AC, todos os tratamentos apresentaram firmeza de polpa superior a $60 \mathrm{~N}$, não havendo diferença estatística entre os mesmos (Tabela 1). De acordo com Corrent et al. (2004), em condições de AC, maçãs 'Royal Gala' apresentam redução de firmeza de polpa menos acentuada do que em $\mathrm{AR}$, o que pode explicar o fato de o 1-MCP não ter apresentado efeito sobre a manutenção da firmeza de polpa na condição de AC.

Não houve diferença estatística quanto à AT (Tabela 1) e ao teor de SS (dados não apresentados) entre os frutos sem e com dano mecânico, em ambos os sistemas de armazenamento e períodos de avaliação. Da mesma forma, outros autores não verificaram efeito do dano mecânico sobre estes atributos em abacate (SANCHES et al., 2008), maçã (STEFFENS et al., 2008) e damasco (DE MARTINO et al., 2006). Contudo, em goiabas (MATTIUZ; DURIGAN, 2001b), houve menor AT nos frutos submetidos ao dano mecânico. A intensidade do dano possivelmente não foi suficiente para provocar aumento no metabolismo dos frutos danificados, uma vez que houve a manutenção dos valores de AT e do teor de SS.

Em maçãs sem dano mecânico, armazenadas em AR, o 1-MCP proporcionou maior AT após sete dias em condição ambiente (Tabela 1), o mesmo não ocorrendo com os teores de SS (dados não apresentados). Estes resultados estão de acordo com os obtidos por Brackmann et al. (2004), que observaram maior AT em maçãs tratadas com 1-MCP, mas não sobre o teor de SS. A diminuição da AT e do teor de SS ocorre como resultado da utilização de substratos no processo respiratório. Segundo Corrent et al. (2004), a manutenção da AT nos frutos tratados com 1-MCP pode ser explicada através da menor atividade metabólica. Em frutos com dano mecânico, não foram observados efeitos do 1-MCP na AT (Tabela 1) e no teor de SS. Esse comportamento pode ser resultado da diminuição dos efeitos do 1-MCP devido à formação de novos sítios de ligação ao etileno. Apesar de o mesmo ligar-se irreversivelmente ao sítio, há o retorno da sensibilidade ao etileno pelos frutos, resultado da formação de novos receptores (BLANKENSHIP;
DOLE, 2003), os quais podem ser induzidos pelo dano (STEFFENS et al., 2008).

Embora tenha sido verificado efeito positivo do 1-MCP sobre a manutenção da AT em AR, o mesmo não foi observado em AC. Os resultados obtidos no presente trabalho concordam com Watkins et al. (2000), os quais encontraram maior AT em diferentes cultivares de maçãs, tratadas com 1-MCP e armazenadas em AR, porém efeitos inconsistentes foram verificados em AC.

Nao se observou diferença estatística entre frutos com e sem dano mecânico quanto ao valor $\mathrm{L}$ da cor da epiderme (dados não apresentados), contudo o dano mecânico causou maior redução no valor L da polpa, em ambas as avaliações e sistemas de armazenamento, indicando que houve escurecimento do tecido na região danificada (Tabela 1). Resultados similares foram obtidos por Steffens et al. (2008) em maçãs submetidas a dano mecânico. Dependendo da intensidade do impacto, pode haver dano no sistema de membranas, levando à descompartimentação das células da polpa na região lesionada e, assim, à oxidação dos compostos fenólicos (STEFFENS et al., 2008).

O tratamento com 1-MCP e o armazenamento em condição de $\mathrm{AC}$ não apresentaram efeito sobre o controle do escurecimento em frutos submetidos ao dano mecânico (Tabela 1). Steffens et al. (2008) não verificaram efeito da aplicação de 1-MCP em maçãs, efetuada antes do dano mecânico, na diminuição do escurecimento na região lesionada. No entanto, estes autores observaram que a aplicação de 1-MCP após a ocorrência do dano mecânico reduziu o escurecimento da região. $\mathrm{O}$ dano mecânico pode induzir a formação de novos receptores de etileno. Desta forma, o tratamento com 1-MCP, após o dano mecânico, impede que o etileno se ligue a estes novos receptores, reduzindo assim a atividade da enzima polifenoloxidase. Isto parece explicar a maior efetividade do 1-MCP na redução do escurecimento do tecido, quando aplicado após o dano mecânico.

A menor área de tecido escurecido no local danificado foi de $2,21 \mathrm{~cm}^{2}$, a qual, de acordo com padrões internacionais de qualidade, inviabilizaria a comercialização destes frutos (PANG et al., 1996). Segundo estes autores, a avaliação da superfície da lesão é mais relevante que o volume para medida do tecido escurecido. Na prática, a medida de área lesionada é importante, pois quantifica o que está prontamente visível ao consumidor (ZEEBROECK et al., 2007; LEWIS et al., 2008). De acordo com Cliff et al. (2002), o tamanho do dano não é o fator mais importante, e, sim, o aspecto visual do fruto danificado.

Para frutos em AR, o tratamento com 1-MCP 
aumentou a área de escurecimento no local danificado na remoção da câmara e, após sete dias em condição ambiente, reduziu o valor de profundidade de tecido escurecido (Tabela 2). Em AC, o tratamento com 1-MCP proporcionou o maior valor de profundidade de escurecimento no local danificado após sete dias de exposição dos frutos em condição ambiente
(Tabela 2). O dano é influenciado por propriedades mecânicas e pela geometria da célula, resistência da parede celular e presença de espaços intercelulares (ZEEBROECK et al., 2007). Desta forma, as diferenças observadas entre os tratamentos podem estar associadas ao formato e/ou às propriedades físicas de cada fruto.

TABELA 1- Firmeza de polpa, acidez titulável e índice de cor (L) de maçãs 'Royal Gala', em função do dano mecânico por impacto, originado pela queda da altura de $20 \mathrm{~cm}$, e da aplicação do 1-MCP, armazenadas durante quatro meses em atmosfera refrigerada (AR) e oito meses em atmosfera controlada (AC), seguido de sete dias de exposição em condição ambiente.

\begin{tabular}{|c|c|c|c|c|c|c|}
\hline \multicolumn{7}{|c|}{ Firmeza de polpa $(\mathrm{N})$} \\
\hline \multirow{3}{*}{ Tratamentos } & \multicolumn{3}{|c|}{--------- AR ------------ } & \multicolumn{3}{|c|}{---------- AC ---------- } \\
\hline & \multirow{2}{*}{\multicolumn{2}{|c|}{$\begin{array}{l}----1-M C P \\
\text { Com }\end{array}$}} & \multirow{2}{*}{ Média } & \multicolumn{2}{|c|}{----- 1-МCP ----- } & \multirow{2}{*}{ Média } \\
\hline & & & & Com & Sem & \\
\hline & & & Saída da & âmara -- & & \\
\hline Sem dano & 67,86 & 56,47 & $62,16 \mathrm{a}$ & 71,03 & 72,51 & $71,77 \mathrm{a}$ \\
\hline Com dano & 66,26 & 57,85 & $62,05 \mathrm{a}$ & 71,71 & 71,49 & $71,59 \mathrm{a}$ \\
\hline Média & $67,06 \mathrm{~A}$ & $57,16 \mathrm{~B}$ & & $71,37 \mathrm{~A}$ & $72,00 \mathrm{~A}$ & \\
\hline \multirow[t]{2}{*}{$\overline{\mathrm{CV} \%}$} & & 5,34 & & & 1,38 & \\
\hline & \multicolumn{6}{|c|}{--------------- Condição ambiente -------------- } \\
\hline Sem dano & 66,61 & 45,90 & $56,25 \mathrm{a}$ & 67,46 & 71,27 & $69,38 \mathrm{a}$ \\
\hline Com dano & 65,27 & 53,34 & $59,30 \mathrm{a}$ & 65,06 & 68,83 & $66,34 \mathrm{a}$ \\
\hline Média & $65,93 \mathrm{~A}$ & $49,62 \mathrm{~B}$ & & $66,26 \mathrm{~A}$ & $70,04 \mathrm{~A}$ & \\
\hline$\overline{\mathrm{CV}} \%$ & & 9,22 & & & 4,68 & \\
\hline \multicolumn{7}{|c|}{ Acidez titulável (meq $\left.100 \mathrm{~mL}^{-1}\right)$} \\
\hline \multicolumn{7}{|c|}{---------------- Saída da câmara--------------- } \\
\hline Sem dano & 3,26 & 3,01 & $3,13 \mathrm{a}$ & 3,30 & 3,51 & $3,40 \mathrm{a}$ \\
\hline Com dano & 3,55 & 2,95 & $3,25 \mathrm{a}$ & 3,34 & 3,59 & $3,46 a$ \\
\hline Média & $3,40 \mathrm{~A}$ & $2,98 \mathrm{~A}$ & & $3,31 \mathrm{~A}$ & $3,55 \mathrm{~A}$ & \\
\hline \multirow[t]{2}{*}{ CV\% } & \multicolumn{3}{|c|}{16,44} & \multicolumn{3}{|c|}{6,23} \\
\hline & \multicolumn{6}{|c|}{ 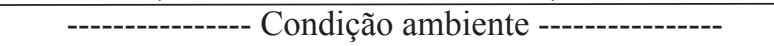 } \\
\hline Sem dano & 3,91Aa & $2,76 \mathrm{Ba}$ & 3,33 & 4,79 & 5,20 & $4,99 \mathrm{a}$ \\
\hline Com dano & $3,37 \mathrm{Aa}$ & 2,97Aa & 3,16 & 4,37 & 3,97 & $4,17 \mathrm{a}$ \\
\hline Média & 3,63 & 2,86 & & $4,58 \mathrm{~A}$ & $4,59 \mathrm{~A}$ & \\
\hline $\mathrm{CV} \%$ & \multicolumn{3}{|c|}{8,33} & \multicolumn{3}{|c|}{19,36} \\
\hline \multicolumn{7}{|c|}{ Cor de polpa (L) no local danificado } \\
\hline \multicolumn{7}{|c|}{------------ Saída da câmara ------------- } \\
\hline Sem dano & 81,18 & 81,69 & $81,43 \mathrm{a}$ & 80,85 & 80,90 & $80,87 \mathrm{a}$ \\
\hline Com dano & 76,68 & 75,19 & $75,93 b$ & 75,95 & 76,20 & $76,07 \mathrm{~b}$ \\
\hline Média & $78,93 \mathrm{~A}$ & $78,44 \mathrm{~A}$ & & $78,40 \mathrm{~A}$ & $78,54 \mathrm{~A}$ & \\
\hline \multirow[t]{2}{*}{$\overline{\mathrm{CV}} \%$} & & 1,58 & & & 1,13 & \\
\hline & \multicolumn{6}{|c|}{ 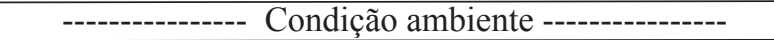 } \\
\hline Sem dano & 81,56 & 82,52 & $82,03 \mathrm{a}$ & 81,41 & 82,19 & $81,79 \mathrm{a}$ \\
\hline Com dano & 75,51 & 75,94 & $75,72 b$ & 75,78 & 75,64 & $75,71 \mathrm{~b}$ \\
\hline Média & $78,53 \mathrm{~A}$ & $79,22 \mathrm{~A}$ & & $78,59 \mathrm{~A}$ & $78,91 \mathrm{~A}$ & \\
\hline $\mathrm{CV} \%$ & & 1,05 & & & 1,51 & \\
\hline
\end{tabular}

Médias seguidas pela mesma letra, minúscula na vertical e maiúscula na horizontal, em um mesmo sistema de armazenamento, não diferem pelo teste de Tukey $(\mathrm{P}<0,05)$. 
TABELA 2 - Área e profundidade do dano de maçãs 'Royal Gala', em função do dano mecânico por impacto, originado pela queda da altura de $20 \mathrm{~cm}$, e da aplicação do 1-MCP, armazenadas durante quatro meses em atmosfera refrigerada (AR) e oito meses em atmosfera controlada (AC), seguido de sete dias de exposição dos frutos em condição ambiente.

\begin{tabular}{|c|c|c|c|c|c|c|}
\hline \multicolumn{7}{|c|}{ Área escurecida no local danificado $\left(\mathrm{cm}^{2}\right)$} \\
\hline \multirow{3}{*}{ Tratamentos } & \multicolumn{5}{|c|}{------------ AR ------------ } & \multirow{3}{*}{ Média } \\
\hline & \multicolumn{2}{|c|}{---- 1-MCP ----- } & \multirow{2}{*}{ Média } & \multirow{2}{*}{\multicolumn{2}{|c|}{ Sem }} & \\
\hline & Com & Sem & & & & \\
\hline & \multicolumn{6}{|c|}{ 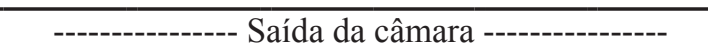 } \\
\hline Sem dano & $0,00 \mathrm{Ab}$ & $0,00 \mathrm{Ab}$ & 0,00 & & 0,00 & $0,00 \mathrm{~b}$ \\
\hline Com dano & $4,03 \mathrm{Aa}$ & $2,84 \mathrm{Ba}$ & 3,43 & & 2,85 & $2,79 \mathrm{a}$ \\
\hline Média & 2,01 & 1,43 & & & $1,42 \mathrm{~A}$ & \\
\hline \multirow[t]{2}{*}{$\mathrm{CV} \%$} & & 14,02 & & & & \\
\hline & \multicolumn{6}{|c|}{---------------- Condição ambiente --------------- } \\
\hline Sem dano & 0,00 & 0,00 & $0,00 \mathrm{~b}$ & & 0,00 & $0,00 \mathrm{~b}$ \\
\hline Com dano & 3,80 & 3,62 & $3,71 \mathrm{a}$ & & 2,21 & $2,23 \mathrm{a}$ \\
\hline Média & $1,90 \mathrm{~A}$ & $1,81 \mathrm{~A}$ & & & $1,10 \mathrm{~A}$ & \\
\hline $\mathrm{CV} \%$ & & 27,58 & & & & \\
\hline \multicolumn{7}{|c|}{ Profundidade de escurecimento no local danificado $(\mathrm{cm})$} \\
\hline \multirow{3}{*}{ Tratamentos } & \multirow{3}{*}{\multicolumn{3}{|c|}{ 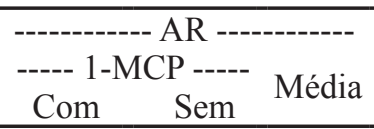 }} & \multirow{2}{*}{\multicolumn{2}{|c|}{----- AC - }} & \multirow{3}{*}{ Média } \\
\hline & & & & & & \\
\hline & & & & Com & Sem & \\
\hline & & & Saída da & câmara & & \\
\hline $\begin{array}{l}\text { Sem dano } \\
\text { Com dano }\end{array}$ & $\begin{array}{l}0,00 \\
0,46\end{array}$ & $\begin{array}{l}0,00 \\
0,42\end{array}$ & $\begin{array}{l}0,00 \mathrm{~b} \\
0,44 \mathrm{a}\end{array}$ & $\begin{array}{l}0,00 \\
0,33\end{array}$ & $\begin{array}{l}0,00 \\
0,39\end{array}$ & $\begin{array}{l}0,00 \mathrm{~b} \\
0,36 \mathrm{a}\end{array}$ \\
\hline Média & $0,23 \mathrm{~A}$ & $0,21 \mathrm{~A}$ & & $0,16 \mathrm{~A}$ & $0,19 \mathrm{~A}$ & \\
\hline \multirow[t]{2}{*}{ CV\% } & & 9,60 & & & 4,69 & \\
\hline & \multicolumn{6}{|c|}{---------------- Condição ambiente---------------- } \\
\hline Sem dano & 0,00 & 0,00 & $0,00 \mathrm{~b}$ & 0,00 & 0,00 & $0,00 \mathrm{~b}$ \\
\hline Com dano & 0,37 & 0,42 & $0,39 \mathrm{a}$ & 0,37 & 0,30 & $0,33 \mathrm{a}$ \\
\hline Média & $0,18 \mathrm{~B}$ & $0,21 \mathrm{~A}$ & & $0,18 \mathrm{~A}$ & $0,15 \mathrm{~B}$ & \\
\hline $\mathrm{CV} \%$ & & 5,78 & & & 7,67 & \\
\hline
\end{tabular}

Médias seguidas pela mesma letra, minúscula na vertical e maiúscula na horizontal, em um mesmo sistema de armazenamento, não diferem pelo teste de Tukey $(\mathrm{P}<0,05)$.

\section{CONCLUSÃO}

O dano mecânico, ocasionado pelo impacto do fruto a uma altura de $20 \mathrm{~cm}$ sobre superfície rígida, não possui efeito sobre a indução do amadurecimento, mas ocasiona escurecimento da polpa em maçãs 'Royal Gala'. O uso do 1-MCP não retarda os efeitos decorrentes do dano mecânico, no entanto proporciona melhor manutenção dos atributos de qualidade em atmosfera refrigerada. A atmosfera controlada preserva a qualidade dos frutos, porém sem efeito sinérgico com o 1-MCP.

\section{REFERÊNCIAS}

BARCHI, G. L.; BERARDINELLI, A.; GUARNIERI, A.; RAGNI, L.; TOTARO FILA, C. Damage to loquats by vibration-simulating intra-state transport. Biosystems Engineering, London, v. 82, n. 3, p. 305-312, 2002.

BLANKENSHIP, S. M.; DOLE, J. M. 1-methylcyclopropene: a review. Postharvest Biology and Technology, Amsterdam, v.28, n.1, p.1-25, 2003. 
BRACKMANN, A.; EISERMANN, A. C.; WEBER, A.; GIEHL, R. F. H.; PAVANELLO, E. P.; BOTH, V. Qualidade da maçã 'Gala' armazenada em atmosfera controlada associada à absorção e ao controle da síntese e da ação do etileno. Ciência Rural, Santa Maria, v.38, n.8, p.2151-2156, 2008.

BRACKMANN, A.; SESTARI, I.; STEFFENS, C. A. ; GIEHL, R. F. H. Qualidade da maçã cv. Gala tratada com 1-metilciclopropeno. Ciência Rural, Santa Maria, v.34, n.5, p.1415-1420, 2004.

CHITARRA, M. I. F.; CHITARRA, A. B. Pós-colheita de frutas e hortaliças: fisiologia e manuseio. 2. ed. Lavras: EDUFLA, 2005. 875p.

CLIFF, M.; SANFORD, K. A.; WISMER, W.; HAMPSON, C. R. Use of digital images for evaluation of factors responsible for visual preference of apples by consumers, Hortscience, Alexandria, v.37, n. 7, p.1127-1131, 2002.

CORRENT, A. R.; PARUSSOLO, A.; GIRARDI, C. L.; ROMBALDI, C. V. Efeito do 1- metilciclopropeno na conservação de maçãs 'Royal Gala' em ar refrigerado e atmosfera controlada. Revista Brasileira de Fruticultura, Jaboticabal, v.26, n.2, p.217-221, 2004.

DAL CIN, V.; RIZZINI, F. M.; BOTTON, A.; TONUTTI, P. The ethylene biosynthetic and signal transduction pathways are differently affected by 1-MCP in apple and peach fruit. Postharvest Biology and Technology, Amsterdam, v.42, n.2, p.125-133, 2006.

DE MARTINO, G.; VIZOVITIS, K.; BOTONDI, R.; BELLINCONTRO, A.; MENCARELLI, F.1$\mathrm{MCP}$ controls ripening induced by impact injury on apricots by affecting SOD and POX activities. Postharvest Biology and Technology, Amsterdam, v.39, n.1, p.38-47, 2006.

DINTWA, E.; ZEEBROECK, M. V.; RAMON, H.; TIJSKENS, E. Finite element analysis of the dynamic collision of apple fruit. Postharvest Biology and Technology, Amsterdam, v.49, n. 2, p.260-276, 2008.
KAAYA, A. N.; NJOROGE, C. K. The effect of physical damage on respiration, chemical and physical parameters in tomato (lycopersicon esclentum) fruit. African Journal of Food, Agriculture, Nutrition and Development, Kenya, v.4, n.2, 2004. Disponível em: $<$ http://www.ajfand.net/Issue-VII-files/ IssueVII-Peer $\% 20$ Reviewed $\% 20$ Article $\% 20 \% 20$ Njoroge.htm>. Acesso em: 15 maio 2008.

LEWIS, R. et al. Characterising pressure and bruising in apple fruit. Wear--, Amsterdam, v. 264, n.1-2, p.37-46, 2008

MAGALHÃES, A. D. et al. Superfícies protetoras na diminuição de danos mecânicos em tomate de mesa. Ciência Rural, Santa Maria, v.37, n.3, p.878881, 2007

MAJUMDER, K.; MAZUMDAR, B. C. Changes of pectic substances in developing fruits of capegooseberry (Physalis peruviana L.) in relation to the enzyme activity and evolution of ethylene. Scientia Horticulturae, Amsterdam, v.96, n.1-4, p.91-101, 2002.

MATTIUZ, B. H.; DURIGAN, J. F. Efeito de injúrias mecânicas na firmeza e coloração de goiabas das cultivares Paluma e Pedro Sato. Revista Brasileira de Fruticultura, Jaboticabal, v.23, n.2, p.277-281, 2001a.

MATTIUZ, B. H.; DURIGAN, J. F. Efeito de injúrias mecânicas no processo respiratório e nos parâmetros químicos de goiabas 'Paluma' e 'Pedro Sato'. Revista Brasileira de Fruticultura, Jaboticabal, v.23, n.2, p.282-287, $2001 \mathrm{~b}$.

MORETTI, C. L.; SARGENT, S. A. Alteração de sabor e aroma em tomates causada por impacto. Scientia Agricola, Piracicaba, v.57, n.3, p.385-388, 2000 .

PANG, D. W.; STUDMAN, C. J.; BANKS, N. H.; BAAS, P. H. Rapid assessment of the susceptibility of apples to bruising. Journal of Agricultural Engeniring Research, Amsterdam, v.64, n.1, p.37-48, 1996. 
QUINTANA, M. E. G.; PAULL, R. E. Mechanical injury during postharvest handling of 'Solo' papaya fruit. Journal of the American Society for Horticultural Science, Alexandria, v.118, n.5, p.618-622, 1993.

SANCHES, J.; DURIGAN, J. F.; DURIGAN, M. F. B. Aplicação de danos mecânicos em abacates e seus efeitos na qualidade dos frutos. Engenharia Agrícola, Jaboticabal, v.28, n.1, p.164-175, 2008.

STEFFENS, C. A.; ESPÍNDOLA, B. P.; AMARANTE, C. V. T.; SILVEIRA, J. P. G.; CHECHI, R.; BRACKMANN, A. Respiração, produção de etileno e qualidade de maçãs "Gala" em função do dano mecânico por impacto e da aplicação de 1-metilciclopropeno. Ciência Rural, Santa Maria, v.38, n.7, p.1864-1870, 2008.
WATKINS, C. B.; NOCK, J. F.; WHITAKER, D. B. Responses of early, mid and late season apple cultivars to postharvest application of 1-methylcyclopropene (1-MCP) under air and controlled atmosphere storage conditions. Postharvest Biology and Technology, Amsterdam, v.19, n.1, p.17-32, 2000.

WATKINS, C. B. The use of 1-methylcyclopropene (1-MCP) on fruits and vegetables. Biotechnology Advances, Kidlington, v.24, n.4, p.389-409, 2006.

ZEEBROECK, M. V.; LINDEN, V. V.; RAMON, H.; BAERDEMAEKER, J.; NICOLAÏ, B.M.; TIJSKENS, E. Impact damage of apples during transport and handling. Postharvest Biology and Technology, Amsterdam, v.45, n.2, p.157-167, 2007. 